\title{
Developing a novel psychographic-behavioral qualitative mapping method for exergames
}

\author{
James Smith ${ }^{1}$, Matthew D. Lee ${ }^{2}$, Louise A. Ellis ${ }^{1}$, Kiran Ijaz $^{3}$ Kathleen Yin ${ }^{3}$ \\ ${ }^{1}$ Centre for Healthcare Resilience and Implementation Science, Australian Institute of \\ Health Innovation, Macquarie University, Sydney, Australia, jim.smith@mq.edu.au, \\ louise.ellis@mq.edu.au \\ ${ }^{2}$ School of Nursing, University of Pennsylvania, Philadelphia, USA, \\ lemat@nursing.upenn.edu
}

${ }^{3}$ Centre for Health Informatics Australian Institute for Health Innovation, Macquarie University, Sydney, Australia,kiran.ijaz@mq.edu.au, kathleen.yin@mq.edu.au

\section{Abstract}

Location-based augmented reality games, used in several smartphone devices, have the potential to improve health outcomes by transforming gaming from a sedentary leisure pursuit to an active leisure pursuit thus having positive physical, psychological and social implications. We consider two games, Harry Potter: Wizards Unite and Pokémon GO, by qualitatively mapping both psychographic and behavioral data to profile groups of players to fully understand how we can better design location-based augmented reality exergames to improve exercise and health. Data was collected through an online open-ended, text-box survey (proforma) hosted on Qualtrics, with participants reached via virtual snowballing. The proforma was posted on four subreddit forums dedicated to Harry Potter: Wizards Unite and Pokémon GO for two weeks, and 1052 participants responded. Our study aligns with a deductive category application, with all highlighted excerpts coded using a predetermined coding scheme. Overall, three themes were identified: 1) player loyalty, 2) player involvement and 3) player constraints. We conclude that psychographic constraints experienced can negatively influence player preference and behavior. However, psychographic enablers such as player involvement with the franchise and player loyalty toward the brand can act to sustain continued gameplay across different player types and should not be underestimated as a powerful influence in decision-making, choice behavior, and behavior change (to improve exercise and health).

Keywords: Augmented reality, Exergames, Harry Potter: Wizards Unite, Pokémon GO, Player typologies, Psychographics

\section{Introduction}

Serious games have a multiple purpose that attaches at least one characterizing goal such as education or health-related benefit (e.g. games for health) to a digital game without compromising player experience $[1,2]$. Exergames are a prominent area of serious games as they include exertion (physical activity) plus video game aimed to increase player's physical activity [3]. Augmented Reality (AR) can enhance engagement by bringing the wonders of a fantasy world to life by altering how players view their physical realities, with the hope for more profound and long-lasting player involvement [4].

Due to the rise of social networks and mobile computing technology, exergames can now incorporate the user's physical location to influence the game world $[3,5]$. These location-based games as exergames are AR games because they augment a virtual world on 
pag. 88

top of our real-world environment to create a hybrid space, giving the illusion of playing in the context of the real world $[3,5,6]$. Smartphone devices make exergames easily accessible and therefore have the potential to increase physical activity across multiple populations [3, 7-12]. With the potential link to attaining multiple health-related benefits, exergames can transform gaming from a sedentary leisure pursuit to an active leisure pursuit having positive physical, social and psychological implications [7, 12-14]. Harry Potter: Wizards Unite (HPWU) and Pokémon GO (PGO) are ideal exergames to compare [3, 12] as these two popular games were designed by the same company called Niantic Inc [15, 16], that incorporated AR by designing and packaging it alongside the same AR digital points of interest (PoIs: represent real-world objects) [3, 10] for easy experiential consumption [17].

According to Laato et al. [3] typical examples of location-based AR exergames include HPWU, PGO, Ingress (Prime) and The Walking Dead: Our World. Laato et al. [3] reported HPWU's having a similar effect to PGO on increasing mild player exercise. Other previous research found that playing PGO increased mild exercise, can be a gateway for exercise for inactive individuals, and provided multi-layered motivation for exercise, including in-game rewards and social features [18]. The authors also highlight that PGO can be integrated into a daily commute, and during other travels, and have the potential to provide other health-related benefits, such as social well-being [18]. More recently, Ellis et al. [12] identified that HPWU and PGO exergames have the potential to promote physical and mental health during the COVID-19 pandemic.

PGO and HPWU currently dominate the location-based AR exergame market [19] by successfully creating a magical and extraordinary player experience that encourages healthy outdoor exploration and social gameplay $[5,6,20]$. In PGO, players take on the role of adventurers on a quest to travel across the land, searching far and wide for fictional creatures called Pokémon, who will appear on the game map once a player is within a given distance of them. Once a Pokémon is found, players may attempt to capture items called Pokéballs (thrown using a simple flicking motion), which they can restock by visiting PoIs called gyms or Pokéstops [3]. HPWU players are made to feel like part of a complex story set in the Wizarding World, with players taking on the role of members of a special Task Force investigating the truth behind a mysterious phenomenon known as the Calamity, which is causing chaos around the world. To do this, players seek out objects displaced from the proper places and times, on which traces of the Calamity's magic may yet be found. To extract these traces (and return these objects to where and when they belong), players must quickly and accurately trace the pattern of a spell on the screen, with many traces requiring multiple successful casts to fully extract. Each spell attempt - successful or failed - consumes a certain amount of spell energy, a limited resource which can only be restored at PoIs [3].

It is important to note however, that AR design factors for exergames and commercial ends are not always aligned, which can create tension between aspects of AR games designed for health-related benefits and those intended to promote commercial success. This provides an interesting and complex dynamic that is highly dependent on how both affect player preference and behavior $[1,3,4]$. As such, there is a pressing need to better understand the influencing factors that hinder or enable player preferences and behavior for different player groups, as this can influence player choice behavior and behavior change (e.g., improving health-related outcomes).

\section{Theoretical background}

\subsection{Segmentation Theory}

Traditionally, researchers have used Segmentation Theory (dividing participants into segments to understand preferences and behaviors) to inform serious game design [21-24]. Demographic segmentation (descriptive features) using gender or age, etc. were found to 
be too simplistic as well as problematic in the gaming literature, with some researchers suggesting that a focus on such descriptive features is insufficient to determine pertinent differences between game players [24-26]. Consequently, demographic aspects have not been of interest in research on player typologies [21].

Turning to behavioral descriptors in segmentation, these can include current and former players [27, 28]. However, more detailed behavioral descriptors exist and have been used to segment different player behaviors based on behavioral engagement typologies [24, 27]. Initially, this started with behavioral segmentation of two explicit groups consisting of casual and hardcore players $[19,24]$. This casual/hardcore binary is also expanded upon in the game literature to provide a more comprehensive player behavioral range by including both mid-core players (that lie in-between the two extremes of casual and hardcore players) $[12,29]$, and those who are yet to establish any type of player identity (no-identification) $[12,27,30]$.

However, immediate questions remain: what factors underlie player preferences and behaviors, and how can we harness this knowledge to improve AR game design? Running parallel to this work is a complimentary body of literature on health-related benefits based on psychographic variables consisting of constraints, involvement, and loyalty. This work provides important types of barriers and enablers for attaining healthrelated benefits [31-33]. Given serious games goal for players to attain health-related benefits [1, 3], researchers in this field should seriously consider how constraints, involvement and loyalty impact upon player preference and behavior. Furthermore, few studies in the serious games literature have applied qualitative methods to Segmentation Theory [22], despite qualitative methods potential benefit to provide a deeper understanding of player preference and behavior [24].

\section{Methodological contribution}

A good method or tool is currently lacking in the literature on studying different player typologies [21]. As shown in Table 1 and Table 2, we introduce a novel qualitative mapping method to segmentation in our paper for the first time, that utilizes both behavioral descriptors (player typologies and player status) and psychographic (constraints, involvement, loyalty) aspects of player populations to explore the different factors that interact to either enable or hinder player preferences and behavior. We also recognize that players are heterogeneous in their levels of constraints (structural, interpersonal \& intrapersonal) [32-35], involvement (attraction, sign-value, centrality, \& risk) [32-36], and loyalty (attitudinal and word-of-mouth) [32-35] (See Table 1-2). Therefore, our combined psychographic-behavioral mapping method to segment and sort different player profiles into meaningful homogenous subgroups is an important endeavor for developing tailored AR game design strategies to promote health-related benefits [33, 37].

At present, in-depth internal psychographics, including player constraints, involvement, and loyalty, remains hidden from game designers and health practitioners alike [31-33, 35, 38-41]. Yet, this information is highly useful in AR serious game design with the goal for people to attain health-related benefits. Constraints that people are exposed to during play can negatively influence player behavior and their preferences $[35,38,41$, 42]. Likewise, enablers such as involvement is "an unobservable state of motivation, arousal, or interest towards an activity" (p.246) [43], that has a well-established relationship to loyalty in the maintenance of strong attitudes toward resistance to change preferences [31, 35, 44, 45] (See Table 1). Together, an understanding of constraints and enablers (such as involvement and loyalty) can provide game designers and other stakeholders a better understanding of how to implement design changes or modifications to enhance player perceptions and help players attain health-related benefits.

Accordingly, the following aim is formulated: To develop a novel psychographicbehavioral qualitative mapping method to understand patterns between how player 
pag. 90

preference and play behavior is affected by perceived constraints, involvement and loyalty. Our study is providing a novel methodology for studying the pattern of play. We are overlaying self-defined behavioral patterns (such as 'hardcore' and 'casual') with constraining and enabling factors, thus providing a possibility of targeting player subgroups by identifying specific constraints and enablers, which could improve future serious exergame use and design. To our knowledge, the factors we are assessing have not been combined in this context. Our novel qualitative mapping method will therefore help to identify what different player identifications experience in relation to constraints, involvement, and loyalty, thus providing valuable insight into player behavior and preference.

Table 1. Definitions from studies establishing key behavioral features used in serious games

\begin{tabular}{|c|c|c|c|c|c|c|}
\hline Authors & Features & \multicolumn{5}{|c|}{ Behavioral descriptors } \\
\hline $\begin{array}{l}\text { Hamari \& } \\
\text { Tuuunanen [27]; } \\
\text { Tseng [28] }\end{array}$ & Player status & \multicolumn{2}{|c|}{$\begin{array}{l}\text { Current player of either (or } \\
\text { both) HPWU or POGO }\end{array}$} & \multicolumn{3}{|c|}{$\begin{array}{l}\text { Former player of either (or both) } \\
\text { HPWU or POGO }\end{array}$} \\
\hline $\begin{array}{l}\text { Dunham et al. } \\
\text { [19]; Ellis et al. } \\
\text { [12]; Ip \& Jacobs } \\
\text { [24]; Kirman \& } \\
\text { Lawson [30]; } \\
\text { Loporcaro et al. } \\
\text { [23]; Manero et al. } \\
\text { [22]; Tuunanen \& } \\
\text { Hamari [21]; } \\
\text { Yee [29] }\end{array}$ & $\begin{array}{l}\text { Player self- } \\
\text { identification }\end{array}$ & $\begin{array}{l}\text { Hardcore: } \\
\text { Those who invest a } \\
\text { significant amount } \\
\text { of their recreational } \\
\text { time and resources } \\
\text { to gaming, and who } \\
\text { also have more } \\
\text { knowledge and } \\
\text { skills in games }\end{array}$ & $\begin{array}{l}\text { In-be } \\
\text { (mid- } \\
\text { Those } \\
\text { that e } \\
\text { betwe } \\
\text { hardc } \\
\text { casua }\end{array}$ & & $\begin{array}{l}\text { Casual: } \\
\text { Those who } \\
\text { play games } \\
\text { casually, in } \\
\text { short } \\
\text { sessions or } \\
\text { infrequently }\end{array}$ & $\begin{array}{l}\text { No- } \\
\text { identification: } \\
\text { Those players } \\
\text { who have not } \\
\text { yet established } \\
\text { a clear player } \\
\text { identification }\end{array}$ \\
\hline
\end{tabular}

Table 2. Definitions from studies establishing key psychographic factors from the healthrelated benefits literature

\begin{tabular}{|c|c|c|c|c|c|}
\hline Authors & Psychographic & \multicolumn{4}{|c|}{ Psychographic factors } \\
\hline $\begin{array}{l}\text { Alexandris et al. } \\
\text { [32,33]; Jun et al. } \\
\text { [38]; Smith \& } \\
\text { Smith [35]; Smith } \\
\text { [41] }\end{array}$ & $\begin{array}{l}\text { Constraints } \\
\text { (Barrier) }\end{array}$ & $\begin{array}{l}\text { Structural: } \\
\text { Constraints external } \\
\text { to an individual } \\
\text { (e.g., distance, cost) }\end{array}$ & $\begin{array}{l}\text { Interpersonal: } \\
\text { Inability to find } \\
\text { partners to } \\
\text { participate } \\
\text { (e.g., lack of } \\
\text { other players) } \\
\end{array}$ & \multicolumn{2}{|c|}{$\begin{array}{l}\text { Intrapersonal: } \\
\text { Internal psychological } \\
\text { constraints (e.g., confidence, } \\
\text { lack of interest) }\end{array}$} \\
\hline $\begin{array}{l}\text { Alexandris et al. } \\
\text { [32, 33]; Havitz et } \\
\text { al. [31]; Smith \& } \\
\text { Smith [35]; Smith } \\
\text { [41] }\end{array}$ & $\begin{array}{l}\text { Involvement } \\
\text { (Enabler) }\end{array}$ & $\begin{array}{l}\text { Sign-value: } \\
\text { Symbolic value - an } \\
\text { individual can } \\
\text { express their } \\
\text { identity through the } \\
\text { activity }\end{array}$ & $\begin{array}{l}\text { Centrality: } \\
\text { The degree to } \\
\text { which the } \\
\text { activity is } \\
\text { central to one's } \\
\text { life }\end{array}$ & $\begin{array}{l}\text { Attraction: } \\
\text { Perceived } \\
\text { importance } \\
\text { and hedonic } \\
\text { value }\end{array}$ & $\begin{array}{l}\text { Risk: } \\
\text { The perceived } \\
\text { or actual risk of } \\
\text { switching to } \\
\text { other games }\end{array}$ \\
\hline $\begin{array}{l}\text { Howat et al. [45] } \\
\text { [39, 40] Mahony } \\
\text { et al. [40]; } \\
\text { Smith \& Smith } \\
\text { [35]; Smith [41]; } \\
\text { Tsiotsou et al. [39] }\end{array}$ & $\begin{array}{l}\text { Loyalty } \\
\text { (Enabler) }\end{array}$ & $\begin{array}{l}\text { Attitudinal: } \\
\text { The affection held } \\
\text { toward the brand }\end{array}$ & \multicolumn{3}{|c|}{$\begin{array}{l}\text { Word-of-Mouth recommendation: } \\
\text { Behavioral intention of word-of-mouth } \\
\text { recommendation }\end{array}$} \\
\hline
\end{tabular}




\section{Methods}

A qualitative approach was used by applying a combined psychographic-behavioral qualitative methodology to explore both psychographic domains (constraints, involvement, and loyalty) [32, 33, 35, 41] and behavioral descriptors (player status and player selfidentification) (see Table 1). Ethical approval was obtained from the Macquarie University Human Research Ethics Committee for Medical Sciences (Reference No: 52019601512435).

\subsection{Sample and recruitment}

We conducted a qualitative proforma in 2020 ( 2 February - 1 March 2020 inclusive) as part of a larger study to examine PGO and HPWU use and player experience. Participant recruitment was conducted online via four subreddit forums dedicated to PGO or HPWU (r/WizardsUnite, $\mathrm{r} /$ PokemonGO, $\mathrm{r} /$ harrypotterwu, and $\mathrm{r} /$ TheSilphRoad). A recruitment post was pinned to the top of each subreddit from 2 February to 1 March 2020, directing individuals to the participant information page via Qualtrics. Participants were informed that participation was voluntary, that they could withdraw at any time before submitting their final responses, and that to be eligible they needed to be 18 years or older and have played the English versions of PGO or HPWU for at least a week. Those who consented to participate were directed to the open-ended, text-box survey (proforma) which took 15 to 20 minutes to complete. No incentives were offered for taking part. Participants were informed not to provide any identifiable personal information. IP addresses of participants were recorded by Qualtrics to identify repeat visits. Duplicate entries were not permitted after the participant had submitted the proforma. The demographic information from 1052 participants is shown in Table 3.

Table 3. Demographic information

\begin{tabular}{l|l}
\hline Sample characteristics & Number of participants \\
\hline Gender & \\
\hline Male & 381 \\
Female & 470 \\
Other/unindicated & 201 \\
\hline Age & \\
\hline $18-25$ years old & 240 \\
26-35 years old & 460 \\
36-45 years old & 183 \\
46-55 years old & 80 \\
$>55$ years old & 43 \\
Unindicated & 46 \\
\hline Country of residence & \\
\hline USA & 515 \\
Europe & 292 \\
Other Americas & 87 \\
Oceania & 62 \\
Asia & 40 \\
Middle East & 9 \\
Africa & 3 \\
Unindicated & 44 \\
\hline
\end{tabular}

\subsection{Proforma (open-ended, text-box survey)}

The proforma included a total of 25 open-ended questions. Proformas differ from structured interviews or closed question surveys $[46,47]$ which are highly formalized and can be rigid. Instead, the proforma is a qualitative data collection tool taking the form of an open-ended, 
pag. 92

text-box survey, containing several specific open-ended questions [48, 49]. Proformas are designed to encourage expansive answers from participants. To collect additional participant information, adaptations to traditional development and application of the proforma allowed for the addition of categorical behavioral descriptor type questions such as player self-identification groups (hardcore, in-between, casual, no identification) and player status (current or former player).

\subsection{Analysis}

Players of PGO or HPWU were asked to categorize their gameplay style based on the behavioral descriptors of hardcore, in-between, casual, with a fourth category for those who had no idea how to identify themselves (no identification). Therefore, differences in constraints, involvement and loyalty between each group were evaluated based on selfreported behavioral descriptors. The second level of behavioral data was also used to categorize participant profiles based on whether they were current or former players (discontinued one or both games).

We extracted psychographic characteristics (perceived constraints, involvement, and loyalty) $[32,33,35,41]$ from replies in the open-text proforma questions. The two behavioral levels of 1) player status - whether the player is a current player or former player of the game and; 2) player self-identification group - how the player self-identifies themselves (casual, in-between, hardcore, no-identification) were juxtaposed with the psychographic aspects of constraints, involvement and loyalty in the analysis, with the data management facilitated by using NVivo 12 Plus (QSR International) [50]. Data were analysed using Framework Analysis [51] which is a qualitative framework that is aptly suited for mapping and coding framework domains. Our coding framework is based on previous work $[34,35]$, and provide a clear coding structure to apply on data to specify and examine loyalty, involvement, and constraint domains, forming our codebook. This involved a five-step process (familiarization, identifying a thematic framework, indexing, charting, mapping and interpretation) [51].

The research coders identified and categorized the factors (word-of-mouth, centrality, distance, etc.) to their domains (constraints, involvement, loyalty) derived from an analysis of answers from open-ended text-box questions. By assigning framework component labels where appropriate, the initial coding scheme was reviewed, contextualized and adapted. The coding process was validated by sharing the coding and using the coding framework to code the text as well as by reporting coded text back to the larger group. Our coding process included JS training ML and KY to use the coding framework. Three questions were initially coded and cross-checked to determine if we were all coding in the same way. We validated our coding process by coming together as a team and discussing and reflecting on any discrepancies in our initial coding. Once the coding framework was established, we progressed with the coding process for the remaining openended questions. Discrepancies that we could not settle through our coding team were resolved through the wider team with JS, KY \& ML reporting findings back to the larger team on a regular basis.

The research team regularly met to discuss data and as demonstrated above this involved an iterative process until consensus was met. Data was sifted, charted, and sorted that addressed key domains of the framework. Finally, the findings from the qualitative mapping method were visually displayed $[52,53]$ by juxtaposing psychographic factors and behavioral descriptors.

\section{Results}

A summary of the respondent's player status and self-identification behavioral descriptors of those participants responding to the open-ended, text box proforma are shown in Table 4. Themes and related sub-themes are outlined in Table 5. 
Table 4. Player status and self-identification descriptors of the sample

\begin{tabular}{l|l|l}
\hline Self-identification characteristics & n & N \\
\hline HPWU current players & & 512 \\
Player self-identification & 38 & \\
Group one: No identification & 295 & \\
Group two: Casual & 137 & \\
Group three: In-between & 42 & \\
Group four: Hardcore & & 90 \\
\hline HPWU former players & 8 & \\
Player self-identification & 34 & \\
Group one: No identification & 35 & \\
Group two: Casual & 13 & \\
Group three: In-between & & 550 \\
Group four: Hardcore & 34 & \\
\hline PGO current players & 245 & \\
Player self-identification & 189 & \\
Group one: No identification & 82 & \\
Group two: Casual & & \\
Group three: In-between & 13 & \\
Group four: Hardcore & 91 & \\
\hline PGO former players & 36 & \\
Player self-identification & 12 & \\
\hline Group one: No identification & & \\
Group two: Casual & & \\
Group three: In-between & Group four: Hardcore &
\end{tabular}

Table 5. Key themes and related sub-themes

\begin{tabular}{l}
\hline Themes \\
\hline Theme 1: Player Loyalty \\
\hline Sub-themes: \\
Attitudinal (attitudes towards the brand) \\
Word-of-mouth recommendations (adoption based on sources of recommendation) \\
\hline Theme 2: Player Involvement \\
\hline Sub-themes: \\
Sign-value (represents the symbolic value of playing PGO/HPWU) \\
Risk of switching sustainers (risk of making a bad choice in switching) \\
Centrality (how central the game is to one's life). \\
Attraction (activity importance and pleasure gained) \\
\hline Theme 3: Player Constraints \\
\hline Sub-themes: \\
Distance (the distance one needs to travel to participate) \\
Lack of time (wait time between tasks and waiting for others) \\
Lack of access/opportunities to play (bugs, glitches, and faulty game mechanics) \\
External obligations/other priorities (competing obligations) \\
Costs (Cost to play) \\
Lack of knowledge and understanding (lack of understanding of game mechanics) \\
Lack of interest (boredom and the repetitiveness) \\
Lack of confidence (lack of confidence in ability to deal with the difficulty of the game) \\
Lack of significant others (lack of others to play with)
\end{tabular}


pag. 94

\subsection{Presentation of the qualitative mapping method}

The final step was to visually represent a simplified account $[52,53]$ of player preference and behavior, supported by the use of NVivo 12 Plus (QSR International) [50]. This is demonstrated through the qualitative psychographic-behavioral summary of results Table (See Table 6) highlighting patterns of relationships based on the different factors across current and former player views and self-identification types. The summary of data on player preference and behavior shown in our qualitative map (See Table 6) represent the 'presence' or 'absence' of constraints (showing constraints can be experienced in several ways) and enablers (showing multiple enablers). The qualitative mapping method can therefore be used to show patterns across different factors shown in the psychographicbehavioral mapping method. For our qualitative mapping method, it is not about the number of times something is mentioned, it is about hermeneutics and patterns of themes that Table 6 displays [52-54]. 
Table 6. A psychographic-behavioral qualitative mapping method of current players and former players and the interaction across constraints and enablers

\begin{tabular}{|c|c|c|c|c|c|c|c|c|c|c|c|c|c|c|c|c|c|}
\hline \multirow{2}{*}{\multicolumn{3}{|c|}{ Behavioral descriptors }} & \multicolumn{15}{|c|}{ Psychographics } \\
\hline & & & \multicolumn{9}{|c|}{ Player Constraints } & \multicolumn{6}{|c|}{ Player Enablers } \\
\hline $\begin{array}{l}\text { Player } \\
\text { Identification } \\
\text { Group }\end{array}$ & $\begin{array}{l}\text { Player } \\
\text { Status }\end{array}$ & $\begin{array}{l}\text { Player } \\
\text { Game } \\
\text { Type }\end{array}$ & 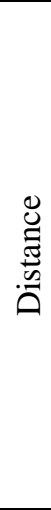 & 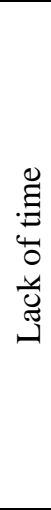 & 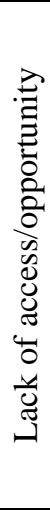 & 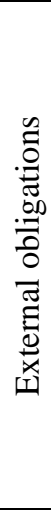 & $\overrightarrow{\tilde{n}}$ & 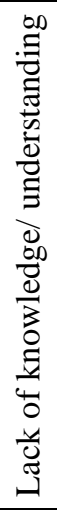 & 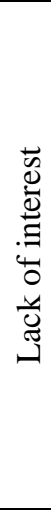 & 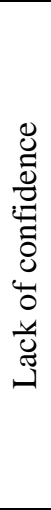 & 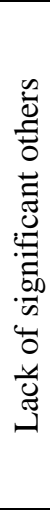 & 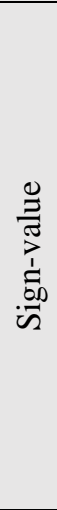 & 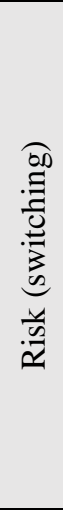 & : & 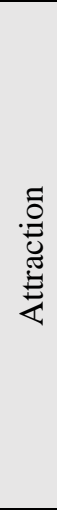 & 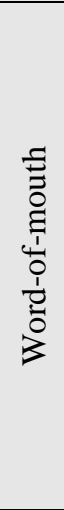 & 堂 \\
\hline \multirow{2}{*}{ Hardcore } & Current & HPWU & $\mathrm{X}$ & $\mathrm{X}$ & $\checkmark$ & $\checkmark$ & $\checkmark$ & $\mathrm{X}$ & $\checkmark$ & $\mathrm{X}$ & $\checkmark$ & $\checkmark$ & $\checkmark$ & $\checkmark$ & $\checkmark$ & $\checkmark$ & $\checkmark$ \\
\hline & Current & PGO & $X$ & $X$ & $\checkmark$ & $\checkmark$ & $\checkmark$ & $\mathrm{X}$ & $\checkmark$ & $\checkmark$ & $\checkmark$ & $\checkmark$ & $\checkmark$ & $\checkmark$ & $\checkmark$ & $\checkmark$ & $\checkmark$ \\
\hline \multirow{2}{*}{ Hardcore } & Former & HPWU & $X$ & $\checkmark$ & $\checkmark$ & $\checkmark$ & $\checkmark$ & $\mathrm{X}$ & $\checkmark$ & $\checkmark$ & $\checkmark$ & $\checkmark$ & $\mathrm{X}$ & $\checkmark$ & $\checkmark$ & $\mathrm{X}$ & $\checkmark$ \\
\hline & Former & PGO & $X$ & $\mathrm{X}$ & $\checkmark$ & $\checkmark$ & $X$ & $X$ & $\checkmark$ & $\checkmark$ & $\checkmark$ & $\checkmark$ & $\mathrm{X}$ & $\mathrm{X}$ & $\checkmark$ & $\checkmark$ & $\checkmark$ \\
\hline \multirow{2}{*}{ In-between } & Current & HPWU & $\checkmark$ & $\checkmark$ & $\checkmark$ & $\checkmark$ & $\checkmark$ & $X$ & $\checkmark$ & $\checkmark$ & $\checkmark$ & $\checkmark$ & $\checkmark$ & $\checkmark$ & $\checkmark$ & $\checkmark$ & $\checkmark$ \\
\hline & Current & PGO & $\checkmark$ & $\mathrm{X}$ & $\checkmark$ & $\checkmark$ & $\checkmark$ & $X$ & $\checkmark$ & $\checkmark$ & $\checkmark$ & $\checkmark$ & $\checkmark$ & $\checkmark$ & $\checkmark$ & $\checkmark$ & $\checkmark$ \\
\hline
\end{tabular}




\begin{tabular}{|c|c|c|c|c|c|c|c|c|c|c|c|c|c|c|c|c|c|}
\hline \multirow{2}{*}{\multicolumn{3}{|c|}{ Behavioral descriptors }} & \multicolumn{15}{|c|}{ Psychographics } \\
\hline & & & \multicolumn{9}{|c|}{ Player Constraints } & \multicolumn{6}{|c|}{ Player Enablers } \\
\hline $\begin{array}{l}\text { Player } \\
\text { Identification } \\
\text { Group }\end{array}$ & $\begin{array}{l}\text { Player } \\
\text { Status }\end{array}$ & $\begin{array}{l}\text { Player } \\
\text { Game } \\
\text { Type }\end{array}$ & 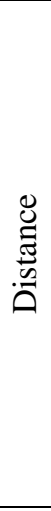 & 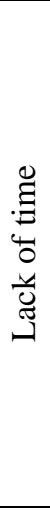 & 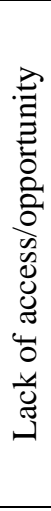 & 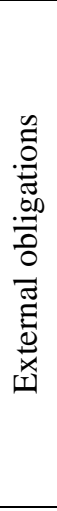 & ì & 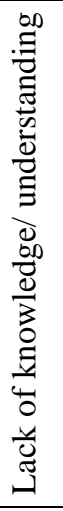 & 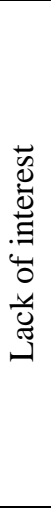 & 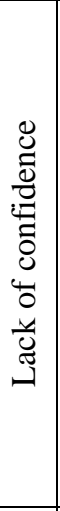 & 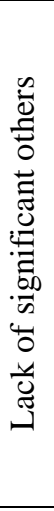 & 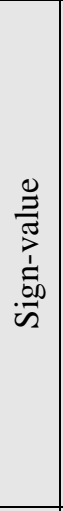 & 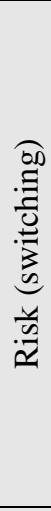 & 疍 & 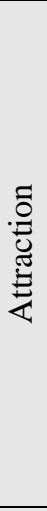 & 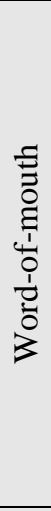 & 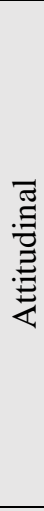 \\
\hline \multirow{2}{*}{ In-between } & Former & HPWU & $\mathrm{X}$ & $\checkmark$ & $\checkmark$ & $\checkmark$ & $\checkmark$ & $\checkmark$ & $\checkmark$ & $\checkmark$ & $\checkmark$ & $\checkmark$ & $\checkmark$ & $\checkmark$ & $\checkmark$ & $\checkmark$ & $\checkmark$ \\
\hline & Former & PGO & $\mathrm{X}$ & $\mathrm{X}$ & $\checkmark$ & $\checkmark$ & $\checkmark$ & $\checkmark$ & $\checkmark$ & $\checkmark$ & $\checkmark$ & $\checkmark$ & $\mathrm{X}$ & $\checkmark$ & $\checkmark$ & $\checkmark$ & $\checkmark$ \\
\hline \multirow{2}{*}{ Casual } & Current & HPWU & $\checkmark$ & $\checkmark$ & $\checkmark$ & $\checkmark$ & $\checkmark$ & $X$ & $\checkmark$ & $\checkmark$ & $\checkmark$ & $\checkmark$ & $\checkmark$ & $\checkmark$ & $\checkmark$ & $\checkmark$ & $\checkmark$ \\
\hline & Current & PGO & $\mathrm{X}$ & $\mathrm{X}$ & $\checkmark$ & $\checkmark$ & $\checkmark$ & $\mathrm{X}$ & $\checkmark$ & $\checkmark$ & $\checkmark$ & $\checkmark$ & $\checkmark$ & $\checkmark$ & $\checkmark$ & $\checkmark$ & $\checkmark$ \\
\hline \multirow{2}{*}{ Casual } & Former & HPWU & $\checkmark$ & $\checkmark$ & $\checkmark$ & $\checkmark$ & $\checkmark$ & $X$ & $\checkmark$ & $\checkmark$ & $\checkmark$ & $\checkmark$ & $\checkmark$ & $\checkmark$ & $\checkmark$ & $\checkmark$ & $\checkmark$ \\
\hline & Former & PGO & $X$ & $\checkmark$ & $\checkmark$ & $\checkmark$ & $\checkmark$ & $\checkmark$ & $\checkmark$ & $\checkmark$ & $\checkmark$ & $\checkmark$ & $X$ & $\checkmark$ & $\checkmark$ & $\checkmark$ & $\checkmark$ \\
\hline \multirow{2}{*}{$\begin{array}{l}\text { No } \\
\text { identification }\end{array}$} & Current & HPWU & $\mathrm{X}$ & $\checkmark$ & $\checkmark$ & $\checkmark$ & $\checkmark$ & $\mathrm{X}$ & $\checkmark$ & $\checkmark$ & $\checkmark$ & $\checkmark$ & $\mathrm{X}$ & $\checkmark$ & $\checkmark$ & $\checkmark$ & $\mathrm{X}$ \\
\hline & Current & PGO & $\mathrm{X}$ & $X$ & $\checkmark$ & $\checkmark$ & $\checkmark$ & $\mathrm{X}$ & $\checkmark$ & $\checkmark$ & $\checkmark$ & $\checkmark$ & $X$ & $\checkmark$ & $\checkmark$ & $\checkmark$ & $\mathrm{X}$ \\
\hline
\end{tabular}




\begin{tabular}{|c|c|c|c|c|c|c|c|c|c|c|c|c|c|c|c|c|c|}
\hline \multirow{2}{*}{\multicolumn{3}{|c|}{ Behavioral descriptors }} & \multicolumn{15}{|c|}{ Psychographics } \\
\hline & & & \multicolumn{9}{|c|}{ Player Constraints } & \multicolumn{6}{|c|}{ Player Enablers } \\
\hline $\begin{array}{l}\text { Player } \\
\text { Identification } \\
\text { Group }\end{array}$ & $\begin{array}{l}\text { Player } \\
\text { Status }\end{array}$ & $\begin{array}{l}\text { Player } \\
\text { Game } \\
\text { Type }\end{array}$ & 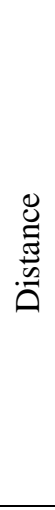 & 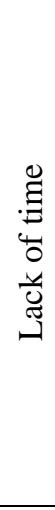 & 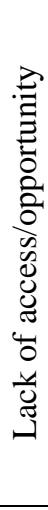 & 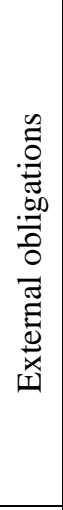 & نे & 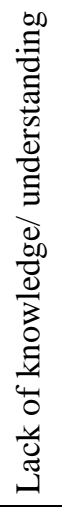 & 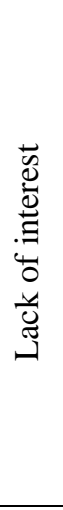 & 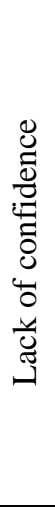 & 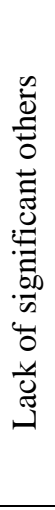 & 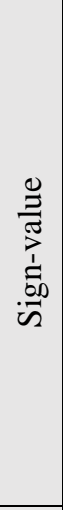 & 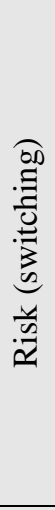 & 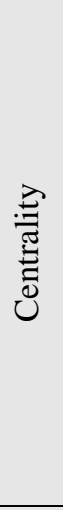 & 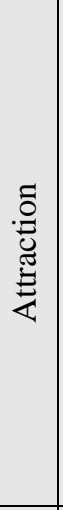 & 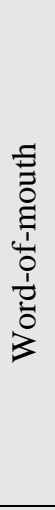 & 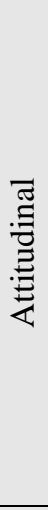 \\
\hline \multirow{2}{*}{$\begin{array}{l}\text { No } \\
\text { identification }\end{array}$} & Former & HPWU & $\mathrm{X}$ & $\checkmark$ & $\checkmark$ & $\checkmark$ & $\mathrm{X}$ & $\checkmark$ & $\checkmark$ & $\checkmark$ & $\checkmark$ & $\checkmark$ & $\mathrm{x}$ & $\checkmark$ & $\checkmark$ & $\checkmark$ & $\mathrm{X}$ \\
\hline & Former & PGO & $\mathrm{x}$ & $\mathrm{x}$ & $\checkmark$ & $\checkmark$ & $\mathrm{X}$ & $\checkmark$ & $\checkmark$ & $\mathrm{x}$ & $\checkmark$ & $\checkmark$ & $\mathrm{X}$ & $\checkmark$ & $\checkmark$ & $\checkmark$ & $\mathrm{X}$ \\
\hline
\end{tabular}

KEY: $\checkmark$ : The extent to which factors were present; X: The extent to which factors were absent 
The different themes and related sub-themes are further explored in detail below.

\subsection{Theme 1: Player Loyalty}

\subsubsection{Attitudinal}

Only the current and former players in the no identification group reported no attitudinal loyalty. In contrast, positive attitudes towards the company brand Niantic revealed that attitudinal loyalty existed across all other groups of current and former players of HPWU and PGO:

"[I am playing] to support Niantic (I'm a former ingress player)." (PGO game: current inbetween player)

\subsubsection{Word-of-mouth recommendations}

Most current and former players across the different player identifications (excluding hardcore HPWU former players) were influenced by word-of-mouth (from friends, partner, family, discord, etc.) resulting in the adoption of either HPWU or PGO games:

"I was playing Pokémon Go at the time and some friends from that community were talking about it [HPWU]." (HPWU game: current no identification player)

\subsection{Theme 2: Player Involvement}

\subsubsection{Sign-value}

Sign-value was present across all current and former player groups. Across different player profiles, sign-value was strongly influenced by the Harry Potter and Pokémon franchise. Sign-value ties and connects people to identify themselves as a fan. For example, participants expressed their preference for the games through a connection to either Harry Potter or Pokémon as a long-term fan. The fantasy world promoted by AR connects the individual to the larger franchise (experiential consumption). This converges across all player groups of HPWU and PGO, for current and former players alike:

"being a loyal Potterhead" (PGO game: current in-between player)

\subsubsection{Risk of switching sustainers}

Interestingly, the no-identification player group did not report risk of switching sustainers. Likewise, former players of PGO also did not report any type of risk of switching sustainers contrasting with their counterparts (current players) who all reported the risk of switching sustainers. For the current player group (hardcore, in-between and casual), switching was offset by Fear Of Missing Out (FOMO) or sunk costs accredited to their involvement, and this was associated with play across both games. Moreover, former in-between and casual players of HPWU mentioned that it was simply impossible to play both games at the same time:

"Sunk costs and a sense of obligation: if I leave my mod [game community moderator] duties, it will be extremely difficult for anyone or even multiple people to take over what I do." (PGO game: current hardcore player)

\subsubsection{Centrality}

For the majority of players (excluding former hardcore players), playing HPWU and/or PGO provides a sense of routine, accomplishment, and reason to go outside, making these two games central to the players' life and movement patterns. Besides the discovery of new places, and plans to fit one's vacation around PGO/HPWU for playtime (causal in-between and hardcore self-identified player types), participants also reported feeling strongly committed to accomplish in-game tasks: 
"I'm going to [City] because of Pokémon go. I've been there before, but this trip is specifically because of Pokémon go and I would not have gone otherwise." (PGO game: current hardcore player)

\subsubsection{Attraction}

Attraction was present across all current and former player groups. Both games were perceived as fun and enjoyable, with player preference geared towards enjoyment and pleasure, a finding that has consistently been shown across current and former player groups alike. It was reported (across different self-identifications of current and former players) by those playing HPWU, that play was largely brought about by having played and enjoyed PGO initially:

"I already loved playing Pokémon go, and Harry Potter therefore seemed perfect." (HPWU game: former casual player)

\subsection{Theme 3: Player Constraints}

\subsubsection{Structural Constraint: Distance}

For HPWU (current in-between and current and former casual players) and PGO players (current in-between players), our study found that a need to travel long distances (e.g., beyond comfortable walking distance) to game-associated locations often necessitated the use of personal transportation. Beyond acting as a constraint to gameplay, this also negatively impacted social interactions, as players who had access to transport often chose to stay in the comfort of their car whilst carrying out collaborative in-game activities. Interestingly, the majority of former HPWU and PGO players did not report distance to be an issue, with one exception of a HPWU casual player reporting that there were not many nearby PoIs around where they live:

"Not much is available within walking distance." (HPWU game: current casual player)

\subsubsection{Structural Constraint: Lack of time}

For current and former players of HPWU, lack of time as a game design issue was mostly related to aspects of wait time between tasks and waiting for people to join for group play, which was a barrier across all HPWU player identifications except for current hardcore players who did not report lack of time as a constraint. Lack of time was only reported by former casual players of PGO, it was stated that getting more out of PGO would have required a significantly larger time investment than they were willing to give:

"Getting more out of the game would require exponentially more time investments" (PGO game: former casual player)

\subsubsection{Structural Constraint: Lack of access/opportunities to play}

Lack of access was a strong and consistent constraint across all player identities of both games. Bugs, glitches, and faulty game mechanics combined with a lack of Foundables for HPWU or the impossibility of obtaining regional Pokémon were mentioned as barriers to engagement across all player types:

"Dislike regional Pokémon - the idea is fun, but realistically most people will never be able to legitimately obtain regionals from all over the world, and as a completionist, this does bother me" (PGO game: current hardcore player)

\subsubsection{Structural Constraint: External obligations/other priorities}

Although family or work obligations were important factors that affected how much different player identifications could engage, players were also unwilling to invest any additional time in gaming, because of this particular constraint. Players across the different player identifications also specifically reported having to choose between the two games or prioritize one over the other, as it was just too difficult to play both games at the same time, 
with their choice of which game to stay with determined by which of the two games that they enjoyed most:

"It was also hard to combine with Pokémon Go and I preferred that game, so I deleted WU [Wizard Unite - HPWU]" (HPWU game: former in-between player)

\subsubsection{Structural Constraint: Costs}

Cost to play was an important factor for current and former players of both games. Neither the hardcore players of PGO nor the no-identification group of former HPWU and PGO groups reported cost to be an issue:

"Super limited spell power resource means you don't do much until you start paying for upgrades to this." (HPWU game: former hardcore player)

\subsubsection{Intrapersonal Constraint: Lack of knowledge and understanding}

Lack of knowledge and understanding was not reported by current HPWU or PGO players. Only former players of HPWU (in-between and no identification players) and some of the former players of PGO (in-between, casual and no-identification) reported a lack of understanding and comprehension of game mechanics:

"Constant changes with no easy way to know how to utilize the new system. i.e., appraisal changes". (PGO game: former casual player)

\subsubsection{Intrapersonal Constraint: Lack of interest}

Across the different player identifications, for current and former players of PGO and HPWU alike, the boredom and the repetitiveness of the HPWU or PGO games were raised as issues. For many HPWU and PGO former players, boredom was often reported as a reason to why they switched over to the other Niantic game (selecting either HPWU or PGO). This type of decrease of interest in play or switching behavior was consistent across all different player groups:

"I realized I liked Pokémon Go a great deal more and WU was taking time away from it." (HPWU game: former casual player)

\subsubsection{Intrapersonal Constraint: Lack of confidence}

For HPWU and PGO player identifications, players across the majority of groups (excluding current hardcore HPWU players and former no-identification PGO players) raised concerns over the difficulty of the game as a game design issue. Many players generally had a lack of confidence in their ability to deal with the difficulty of the game, stating that it was too complicated and presented too much information to process. Many former players of both games echoed these sentiments, as they noted that the games were just too complex and felt it was impossible to progress or win:

"Needs some here's what you do, and why" (POGO game: former in-between player)

\subsubsection{Interpersonal Constraint: Lack of Significant others}

Current players of both games and across different player identifications reported a lack of significant others playing the game, an inability to play with friends living in other countries, and a requirement of having to play with strangers, spoofers (i.e., players who alter their GPS data to 'travel' in the world without physically moving), or toxic local players who negatively influence player perceptions which impacted their play experience. For former players of PGO in the no identification group, a lack of significant others playing was also a reason to switch to HPWU where they had existing playing companions. The need or desire for virtual teammates to replace strangers was also reported, echoing the issues related to group play (waiting time, etc.). Also, for both current and former players, a lack of community and lack of linking with local players were considered problematic:

"Lack of local players (compared with PGO)." (HPWU game: current no identification player). 


\section{Discussion}

\subsection{Key Findings}

Our study considered player preference and behavior in two location-based AR exergames - PGO and HPWU, using a combined psychographic-behavioral qualitative mapping method. Our study reports three themes consisting of 'player loyalty', 'player involvement' and 'player constraints'. Our approach allowed us to gain an enhanced understanding of the similarity and variation between player preferences (based on psychographic-behavioral mapping) for both current players and former players of HPWU and PGO. Through this, we identified factors (sub-themes, e.g., sign-value, word-of-mouth) that related to multiple constraints and enablers that inhibit or allow player preference and behavior to be sustained. Our findings highlight that constraints do not always result in instant defection (quit or stop playing the game) as displayed by the current players who are constrained by a series of barriers, but yet still maintain their preferences and behavior towards PGO and HPWU. Although constraints are those aspects that hinder preferences and behavior, we have also identified important enablers, those aspects that sustain player preferences and behavior. Thus, the practical application of our study is that game designers could borrow from the strength of our qualitative study and utilize our qualitative mapping method in a diagnostic manner to design involvement type strategies within exergames to help support different player identifications $[5,6,20]$.

\subsection{Implications of Findings}

In terms of player typologies [12, 24, 25, 27, 29, 30], psychographic criteria juxtaposed with behavioral descriptors was a useful way to highlight player preferences and behavior across different player identifications of HPWU and PGO. Our qualitative mapping method therefore goes further than psychographics or behavioral descriptors alone. We extend segmentation theory by revealing the importance of qualitative research in our novel psychographic-behavioral mapping method, illuminating not only how the theory is of use, but also how theory can be used in a practical manner to show game designers how preferences and behavior is maintained despite players encountering constraints. If we can harness this type of knowledge by promoting involvement as a game design strategy as well as addressing some constraints directly within the game itself, it could help to prevent some players who may otherwise quit the game as per the former player group. Game designers should therefore focus on ways to enhance player involvement through 'attraction', 'centrality', 'symbolic value' and 'risk of switching' within exergames, since these involvement factors are linked to loyalty (strongly held attachment) to the brand.

Confirming prior studies $[35,55,56]$, player constraints were experienced in several ways for both current and former players and across different player identities. In line with this principle, we also found a similar pattern suggesting constraint factors interacted in several different ways. Smith and Smith [35] state that interactions between constraints are important to identify due to the potential for several (structural, interpersonal intrapersonal) different constraints to interact and operate at the same time, and this can inhibit player preference and behavior. Recently, the role of brand loyalty in HPWU and PGO games were identified as a way to understand player engagement [3]. Our study adds to this literature by showing that despite constraints Niantic manages to maintain loyal players to its brand (brand loyalty), since many players who drop one Niantic game (HPWU or PGO) were shown to do so to prioritize another Niantic game (HPWU or PGO). This was shown in the following constraints reported in our study: external obligations (due to competing demands, a choice between the two games was made), and a lack of significant others (a lack of significant others playing was a reason to switch from PGO over to HPWU). 


\subsection{An Actionable Game Design Strategy using Player Involvement}

For most self-identification types (excluding no-identification), player involvement (selfexpression through symbolic value and positive attitudes toward the franchise) was interrelated with attitudinal loyalty (brand loyalty). Involvement reported in the extant literature is said to positively influence loyalty to maintain preference and behavior [35, 57]. In contrast to this finding, for some player identities, player preference may solely be related to the fun or symbolic and emotional experiences attained. For example, this finding was demonstrated in the no identification group, since this was the only player group not to report any type of attitudinal loyalty or attachment to the Niantic brand. Instead, player preference for this group directly related to a strong attachment to the symbolic elements of play and the pleasure reflected by the hedonic value of play (attraction and sign-value) [4]. Moreover, unlike other player identities, the no-identification players did not report any risk of switching sustainers (FOMO, or sunk costs accredited to their involvement). Game designs that develop opportunities for the no-identification players to connect the franchise (Harry Potter and Pokémon) to the Niantic brand will help to develop a strong brand image for this specific player identification group to establish brand loyalty. This could be further reinforced by Niantic having an online quality presence that continually visibly associates the franchise to the brand, as well as promoting the Niantic brand and its mission at forthcoming sponsored HPWU or PGO events.

AR in both HPWU and PGO provides an altered reality making it a memorable experience $[17,58]$, but this can be experienced differently by how a player may wish or desire to be viewed or portrayed to others [5, 20, 59]. For example, patterns between involvement factors, show sign-value and attraction to be interesting findings to discuss together in more detail. Some in-between and hardcore player identities refer to themselves as 'Potterheads' (a devoted Harry Potter fan) showing sign-value is operating, as these games seem to serve as an extension of how some groups of players want to be perceived as more serious players of the game and is also reflected in the informal label of 'Potterhead' that these groups chose to describe themselves with. Player responses indicate that through AR, fun experiences with the characters can also be reinforcing one's player identity in terms of what they expect and desire from an AR interaction - other player groups refer to having a fantasy of becoming a 'Pokémon trainer in real-life'. This has connotations that player preference and continued behavior is linked to affective and emotional attachment. For example, an individual may feel that they have had or gained something extraordinary as a result of being part of the Harry Potter or the Pokémon world, and are therefore less likely to change their preferences despite potential constraints encountered [35]. Applying this principle to AR serious game design with an understanding of what different player groups expect to experience matched with what they actually experience from an AR interaction may be an avenue of future research to encourage and sustain physical activity potentially leading to further long-term health benefits (7).

Our study indicates that player involvement is one potential game design strategy that is linked to loyalty and therefore can sustain interactive preferences across player types - something with clear implications for health-focused serious games [1]. These rich findings as discussed above, cover several direct AR serious game design implications [6]. In addition, player involvement was also shown to play a central role across current and former players, with some individuals even going so far as to organize their holidays around their gameplay (centrality). For most player identities (excluding former hardcore PGO players), gaming was both central in their lives with gaming experiences being fun and enjoyable. Linking this evidence to AR serious games and its additional element of healthrelated benefits, shows the health-related goal of serious games can and does successfully avoid interfering with the fun elements of the exergame [1]. The idea we pose is an extension of this, by focusing on increasing player involvement (attraction, sign-value centrality and risk of switching sustainers) we can ultimately increase player loyalty to the 
brand, and this indirectly influences health-related outcomes such as maintaining physical activity [1].

\subsection{Future Directions and Limitations}

Our findings suggest that current players of PGO and HPWU who attain enjoyment, symbolic value, risk of switching and centrality maintain their preferences and behavior towards PGO and HPWU despite encountering several constraints. Given that serious games have a hidden agenda of promoting health-related benefits such as physical activity (in HPWU and PGO), if we can keep players loyal, we can keep them physically fit. However, this is an area that needs further exploration in terms of future research in testing different ways to enhance player involvement directly through game design to mitigate against defection and sustain health-related outcomes. This could be further examined by considering its impact on long-term outcomes such as weight-loss when compared to a reference group.

While models of player typologies are ubiquitous in the study of games, these models are often based on the context of players engaging with traditional video games. As such, further research should be done to specifically examine what design factors and gameplay elements could enhance involvement and appeal to the different subgroups within the AR player base [5, 6, 20]. For example, the Player Experience of Needs Satisfaction (PENS) model, that investigates autonomy, competence, intuitive controls, and player's sense of presence during the game play predicts game enjoyment and persistence in video games [60]. Notably, authors argue that usability, game narrative, mechanics, sound, and environment etc. improves players experience and needs satisfaction [61]. A recent work in immersive Virtual Reality exergames suggest PENS validity for designing and evaluating various design features to fuel player's motivation; and further show pronounce differences among those who are focused on physical activity or entertainment [62]. How game design features and usability relate to experiences of AR games is an area that needs further investigation. Our qualitative mapping method to assess preferences and behavior of two exergames through a psychographic-behavioral lens could therefore be translated across other location-based AR exergames. However, a caveat to our findings include the involvement factor called risk of switching sustainers, as this finding showed that FOMO and sunk costs were commonly reported by participants as perceived sustainers of their play, but such aspects could be linked with problematic playing (addiction, manipulation etc.) as reported in the contentious revenue model of free-to-play games (gaining income through voluntary purchases) [63]. As such this also needs to be considered, as the industry requires much needed regulation on this matter with some authors arguing this should come from outside of itself (academic and industry expertise) [63].

\subsection{Conclusion}

Our study provides a novel psychographic-behavioral qualitative mapping method for exergames using real-world research. We identify real-world obstacles that players of HPWU and PGO exergames face and how player involvement can help to shape and create strong attitudes toward resistance to change preferences despite players encountering several significant constraints. Player involvement can enhance our level of understanding as to why players of these two games still participate when they are continually constrained by other factors, such as the lack of other players or time etc. Our qualitative mapping method may also fit the needs of a rapid implementation approach [64]. Our novel method demonstrated here may be translated on a wider basis to other location-based AR exergames, with player involvement potentially providing a mechanism through which we can better understand potential audiences, allowing improvements in the design of healthfocused serious games to better improve health-related outcomes. 


\section{References}

[1] P. Caserman et al., "Quality Criteria for Serious Games: Serious Part, Game Part, and Balance," JMIR serious games, vol. 8, no. 3, p. e19037, 2020, doi: https://doi.org/10.2196/19037.

[2] R. Dörner, S. Göbel, W. Effelsberg, and J. Wiemeyer, Serious Games. Springer, 2016.

[3] S. Laato, S. Hyrynsalmi, S. Rauti, A. K. M. N. Islam, and T. H. Laine, "Location-based Games as Exergames - From Pokémon To The Wizarding World," International Journal of Serious Games, vol. 7, no. 1, pp. 79 - 95, 03/05 2020, doi: https://doi.org/10.17083/ijsg.v7i1.337.

[4] J. Hamari, A. Malik, J. Koski, and A. Johri, "Uses and Gratifications of Pokémon Go: Why do People Play Mobile Location-Based Augmented Reality Games?," International Journal of Human-Computer Interaction, vol. 35, no. 9, pp. 804-819, 2019/05/28 2019, doi: https://doi.org/10.1080/10447318.2018.1497115.

[5] K. Papangelis, M. Metzger, Y. Sheng, H.-N. Liang, A. Chamberlain, and T. Cao, "Conquering the City: Understanding perceptions of Mobility and Human Territoriality in Location-based Mobile Games," Proc. ACM Interact. Mob. Wearable Ubiquitous Technol., vol. 1, no. 3, p. Article 90, 2017, doi: 10.1145/3130955.

[6] X. Fonseca, G. Slingerland, S. Lukosch, and F. Brazier, "Designing for meaningful social interaction in digital serious games," Entertainment Computing, vol. 36, p. 100385, 2021/01/01/ 2021, doi: https://doi.org/10.1016/j.entcom.2020.100385.

[7] B. D. Ma et al., "Pokémon GO and physical activity in Asia: multilevel study," Journal of medical Internet research, vol. 20, no. 6, p. e217, 2018.

[8] K. Hino, Y. Asami, and J. S. Lee, "Step Counts of Middle-Aged and Elderly Adults for 10 Months Before and After the Release of Pokémon GO in Yokohama, Japan," J Med Internet Res, vol. 21, no. 2, p. e10724, 2019/02/05 2019, doi: https://doi.org/10.2196/10724.

[9] T. Althoff, R. W. White, and E. Horvitz, "Influence of Pokémon Go on physical activity: study and implications," Journal of medical Internet research, vol. 18, no. 12, p. e315, 2016, doi: https://doi.org/10.2196/jmir.6759.

[10] S. Laato, S. M. Hyrynsalmi, and M. Paloheimo, "Online multiplayer games for crowdsourcing the development of digital assets," in International Conference on Software Business, 2019: Springer, pp. 387-401, doi: https://doi.org/10.1007/978-3-03033742-1_31.

[11] S. Laato, T. H. Laine, and A. Islam, "Location-based games and the covid-19 pandemic: An analysis of responses from game developers and players," Multimodal Technologies and Interaction, vol. 4, no. 2, p. 29, 2020, doi: https://doi.org/10.3390/mti4020029.

[12] L. Ellis, M. Lee, K. Ijaz, J. Smith, J. Braithwaite, and K. Yin, "COVID-19 as 'Game Changer' for the Physical Activity and Mental Well-Being of Augmented Reality Game Players During the Pandemic: Mixed Methods Survey Study," Journal of Medical Internet Research, 2020, doi: https://doi.org/10.2196/25117

[13] B. A. Primack et al., "Role of video games in improving health-related outcomes: a systematic review," American journal of preventive medicine, vol. 42, no. 6, pp. 630-638, 2012, doi: https://doi.org/10.1016/S0749-3797(12)00267-X.

[14] M. Y. Ni et al., "Augmented reality games as a new class of physical activity interventions? The impact of Pokémon go use and gaming intensity on physical activity," Games for health journal, vol. 8, no. 1, pp. 1-6, 2019, doi: https://doi.org/10.1089/g4h.2017.0181.

[15] Niantic and W. S. Franscisco, "Harry Potter:Wizards Unite," 2019.

[16] Niantic. "Get Up and Go." https://nianticlabs.com/en/products (accessed.

[17] E. J. Arnould and L. L. Price, "River magic: Extraordinary experience and the extended service encounter," Journal of consumer Research, vol. 20, no. 1, pp. 24-45, 1993, doi: https://doi.org/10.1086/209331.

[18] A. G. LeBlanc and J.-P. Chaput, "Pokémon Go: A game changer for the physical inactivity crisis?," Preventive medicine, vol. 101, pp. 235-237, 2017.

[19] J. Dunham, K. Papangelis, N. Lalone, and Y. Wang, Casual and Hardcore Player Traits and Gratifications of Pokémon GO, Harry Potter: Wizards Unite, Ingress. 2021. 
[20] K. Papangelis et al., "Performing the Digital Self: Understanding Location-Based Social Networking, Territory, Space, and Identity in the City," ACM Trans. Comput.-Hum. Interact., vol. 27, no. 1, p. Article 1, 2020, doi: 10.1145/3364997.

[21] J. Tuunanen and J. Hamari, "Meta-synthesis of player typologies," in Proceedings of Nordic Digra 2012 Conference: Games in Culture and Society, Tampere, Finland, 2012.

[22] B. Manero, J. Torrente, M. Freire, and B. Fernández-Manjón, "An instrument to build a gamer clustering framework according to gaming preferences and habits," Computers in Human Behavior, vol. 62, pp. 353-363, 2016/09/01/2016, doi: https://doi.org/10.1016/j.chb.2016.03.085.

[23] J. A. Loporcaro, C. R. Ortega, and M. J. Egnoto, "The Hardcore Scorecard: Defining, Quantifying and Understanding "Hardcore" Video Game Culture," Proceedings of the New York State Communication Association, vol. 2013, no. 2013, p. 7, 2014.

[24] B. Ip and G. Jacobs, "Segmentation of the games market using multivariate analysis," Journal of Targeting, Measurement and Analysis for Marketing, vol. 13, no. 3, pp. 275287, 2005, doi: https://doi.org/10.1057/palgrave.jt.5740154.

[25] R. Ahmad, "Benefit segmentation: a potentially useful technique of segmenting and targeting older consumers," International Journal of Market Research, vol. 45, no. 3, p. 373, 2003, doi: https://doi.org/10.1177/147078530304500302.

[26] J. Forsyth, S. Gupta, S. Haldar, A. Kaul, and K. Kettle, "A segmentation you can act on," The McKinsey Quarterly, p. 7, 1999.

[27] J. Hamari and J. Tuunanen. "Player types: A meta-synthesis." https://trepo.tuni.fi/bitstream/handle/10024/99064/player_types_a_meta synthesis.pdf (accessed December 11, 2020).

[28] F.-C. Tseng, "Segmenting online gamers by motivation," Expert Systems with Applications, vol. 38, no. 6, pp. 7693-7697, 2011/06/01/ 2011, doi: https://doi.org/10.1016/j.eswa.2010.12.142.

[29] N. Yee, "What men and women consider hardcore gaming are not the same," Quantic Foundry, 2018. [Online]. Available: https://quanticfoundry.com/2018/08/01/casualhardcore/\#: : :text=all\%20gaming\%20motivations.,Female $\% 20$ Hardcore\%20gamers\%20are\%20consistently\%20above\%20average\%20acro ss\%20all\%20gaming,in\%20all\%20aspects\%20of\%20gaming.

[30] B. Kirman and S. Lawson, "Hardcore classification: Identifying play styles in social games using network analysis," in International Conference on Entertainment Computing, 2009: Springer, pp. 246-251, doi: https://doi.org/10.1007/978-3-642-04052-8 28.

[31] M. E. Havitz, F. Dimanche, and T. Bogle, "Segmenting the adult fitness market using involvement profiles," Journal of Park and Recreation administration, vol. 12, no. 3, pp. 38-56, 1994. [Online]. Available: https://www.cabdirect.org/cabdirect/abstract/19951803170.

[32] K. Alexandris, C. Kouthouris, D. Funk, and C. Giovani, "Segmenting winter sport tourists by motivation: The case of recreational skiers," Journal of Hospitality Marketing \& Management, vol. 18, no. 5, pp. 480-499, 2009, doi: https://doi.org/10.1080/19368620902950048.

[33] K. Alexandris, "Segmenting recreational tennis players according to their involvement level: A psychographic profile based on constraints and motivation," Managing Leisure, vol. 18, no. 3, pp. 179-193, 2013, doi: https://doi.org/10.1080/13606719.2013.796178.

[34] J. Smith, D. Murray, and G. Howat, "How perceptions of physique can influence customer satisfaction in health and fitness centres," Managing Leisure, vol. 19, no. 6, pp. 442-460, 2014, doi: https://doi.org/10.1080/13606719.2014.920177.

[35] J. Smith and S. Smith, "The Constraint-Effects-Mitigation Involvement Loyalty Model: An Integrative Review," Leisure Sciences, vol. 39, no. 3, pp. 244-260, 2017/05/04 2017, doi: https://doi.org/10.1080/01490400.2016.1192521.

[36] P. G. Schrader and M. McCreery, "The acquisition of skill and expertise in massively multiplayer online games," Educational Technology Research and Development, vol. 56, no. 5, pp. 557-574, 2008/12/01 2008, doi: https://doi.org/10.1007/s11423-007-9055-4.

[37] M. Needham, D. Scott, and J. Vaske, "Recreation Specialization and Related Concepts in Leisure Research," Leisure Sciences, vol. 35, pp. 199-202, 05/01 2013, doi: https://doi.org/10.1080/01490400.2013.780457.

[38] J. Jun, G. Kyle, and A. Mowen, "Market segmentation using perceived constraints," in In: LeBlanc, Cherie; Vogt, Christine, comps. Proceedings of the 2007 northeastern recreation research symposium; 2007 April 15-17; Bolton Landing, NY. Gen. Tech. Rep. 
NRS-P-23. Newtown Square, PA: US Department of Agriculture, Forest Service, Northern Research Station: 1-10., 2008, vol. 23. [Online]. Available: https://www.fs.usda.gov/treesearch/pubs/13830. [Online]. Available: https://www.fs.usda.gov/treesearch/pubs/13830

[39] R. Tsiotsou, "Using visit frequency to segment ski resorts customers," Journal of Vacation Marketing, vol. 12, no. 1, pp. 15-26, 2006/01/01 2006, doi: https://doi.org/10.1177/1356766706059029.

[40] D. F. Mahony, R. Madrigal, and D. A. Howard, "Using the psychological commitment to team (PCT) scale to segment sport consumers based on loyalty," Sport marketing quarterly, vol. 9, no. 1, p. 15, 2000. [Online]. Available: https://business.uoregon.edu/files/media/madrigal-using-psychologicalcommitment_1.pdf.

[41] J. Smith, "Assessing the relative importance of service quality and constraints in predicting loyalty within private health and fitness centres," University of South Australia, Adelaide Australia., Unpublished PhD thesis, 2010.

[42] G. T. Kyle and A. J. Mowen, "An examination of the relationship between leisure constraints, involvement and commitment," in Proceedings of the 2003 Northeastern Recreation Research Symposium. In: Murdy, James, comp. Gen. Tech. Rep. NE-317. ed, 2004, pp. 328-337.

[43] M. E. Havitz and F. Dimanche, "Leisure involvement revisited: Conceptual conundrums and measurement advances," Journal of leisure research, vol. 29, no. 3, pp. 245-278, 1997, doi: https://doi.org/10.1080/00222216.1997.11949796.

[44] S. Lee and D. Scott, "The process of celebrity fan's constraint negotiation," Journal of Leisure Research, vol. 41, no. 2, pp. 137-156, 2009, doi: https://doi.org/10.1080/00222216.2009.11950163.

[45] G. Howat, J. Alikaris, H. March, and P. Howat, "Health-related benefits: Their influence on loyalty and physical activity participation in Australian public aquatic centres," International Journal of Sport Management and Marketing, vol. 12, pp. 73-92, 01/01 2012, doi: https://doi.org/10.1504/IJSMM.2012.051253.

[46] F. Rapport et al., Qualitative research in healthcare: modern methods, clear translation: A White Paper. Sydney, Australia: Macquarie University, 2018.

[47] F. Rapport et al., "Development of an implementation and evaluation strategy for the Australian 'Zero Childhood Cancer' (Zero) Program: a study protocol," BMJ Open, vol. 10, no. 6, p. e034522, 2020, doi: https://doi.org/10.1136/bmjopen-2019-034522.

[48] F. Rapport, E. Francis-Auton, J. Cartmill, T. Ryder, J. Braithwaite, and R. Clay-Williams, "A mobile methods pilot study of surgical spaces: 'fit for purpose? Organisational productivity and workforce wellbeing in workspaces in hospital' (FLOURISH)," BMC Health Services Research, vol. 20, no. 1, p. 78, 2020/02/03 2020, doi: https://doi.org/10.1186/s12913-020-4938-8.

[49] M. Bierbaum et al., "Barriers and Facilitators to Cochlear Implant Uptake in Australia and the United Kingdom," Ear and Hearing, vol. 41, no. 2, 2020, doi: https://doi.org/10.1097/AUD.0000000000000762.

[50] QSR, "NVivo Qualitative Data Analysis Version 12 Plus: QSR International Pty Ltd.," 2019.

[51] J. Ritchie and L. Spencer, "Qualitative data analysis for applied policy research," The qualitative researcher's companion Thousand Oaks, California: SAGE Publications, Inc., 2002, pp. 305-329. [Online]. Available: https://methods.sagepub.com/book/thequalitative-researchers-companion

[52] S. Smith et al., "Partial or total knee replacement? Identifying patients' information needs on knee replacement surgery: a qualitative study to inform a decision aid," Quality of Life Research, vol. 29, no. 4, pp. 999-1011, 2020/04/01 2020, doi: 10.1007/s11136-01902381-9.

[53] S. Parkinson, V. Eatough, J. Holmes, E. Stapley, and N. Midgley, "Framework analysis: a worked example of a study exploring young people's experiences of depression," Qualitative Research in Psychology, vol. 13, no. 2, pp. 109-129, 2016/04/02 2016, doi: 10.1080/14780887.2015.1119228.

[54] N. Blaikie, "Ontology, Ontological," in The SAGE Encyclopedia of Social Science Research Methods, vol. 1-0, M. S. Lewis-Beck, A. Bryman, and T. Futing Liao Eds. Thousand Oaks, California, 2004. 
[55] J. Hubbard and R. C. Mannell, "Testing Competing Models of the Leisure Constraint Negotiation Process in a Corporate Employee Recreation Setting," Leisure Sciences, vol. 23, no. 3, pp. 145-163, 2001, doi: https://doi.org/10.1080/014904001316896846.

[56] J. S. Son, A. J. Mowen, and D. L. Kerstetter, "Testing Alternative Leisure Constraint Negotiation Models: An Extension of Hubbard and Mannell's Study," Leisure Sciences, vol. 30, no. 3, pp. 198-216, 2008, doi: https://doi.org/10.1080/01490400802017308.

[57] G. S. Day, "A two-dimensional concept of brand loyalty," Journal of Advertising Research, no. 9, pp. 29-35, 1969.

[58] E. J. Arnould, L. Price, and G. M. Zinkhan, "Consumers," (in English), 2004. [Online]. Available: http://books.google.com/books?id=K6zxAAAAMAAJ.

[59] R. W. Belk, "Materialism: Trait aspects of living in the material world," Journal of Consumer research, vol. 12, no. 3, pp. 265-280, 1985, doi: https://doi.org/10.1086/208515.

[60] R. M. Ryan, C. S. Rigby, and A. Przybylski, "The motivational pull of video games: A self-determination theory approach," Motivation and emotion, vol. 30, no. 4, pp. 344-360, 2006, doi: https://doi.org/10.1007/s11031-006-9051-8.

[61] S. Rigby and R. M. Ryan, Glued to games: How video games draw us in and hold us spellbound: How video games draw us in and hold us spellbound. AbC-CLIo, 2011.

[62] K. Ijaz, N. Ahmadpour, Y. Wang, and R. A. Calvo, "Player Experience of Needs Satisfaction (PENS) in an Immersive Virtual Reality Exercise Platform Describes Motivation and Enjoyment," International Journal of Human-Computer Interaction, vol. 36, no. 13, pp. 1195-1204, 2020/08/08 2020, doi: https://doi.org/10.1080/10447318.2020.1726107.

[63] K. Alha, "The Rise of Free-to-Play: How the Revenue Model Changed Games and Playing," 2020.

[64] J. Smith et al., "The rise of rapid implementation: a worked example of solving an existing problem with a new method by combining concept analysis with a systematic integrative review," (in eng), BMC Health Services Research, vol. 20, p. 449, 2020, doi: 10.1186/s12913-020-05289-0. 